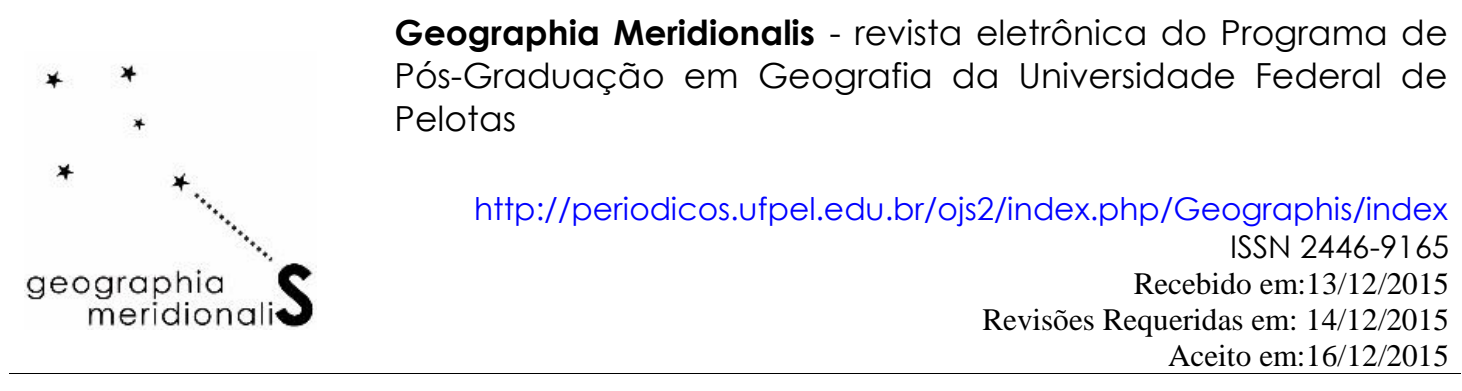

\title{
NOTA TÉCNICA REFERENTE À CONSTRUÇÃO DO DIQUE DE CONTENÇÃO NO PONTAL DA BARRA - LARANJAL (PELOTAS, RS)
}

Anderson Rodrigo Estevam da Silva Anderson Weber Pereira Ândrea Lenise de Oliveira Lopes Anelize Milano Cardoso

Bianca Marques Maio

Luciano de Jesus da Costa Ribeiro Marisa Helena Gonsalves de Moura Rodrigo de Oliveira Siqueira Viviane Spiering Patrícia Souza da Silva Universidade Federal de Pelotas Mestrandos do Programa de Pós-Graduação em Geografia

Tatiane Oliveira Delamare William Gonçalves Lemos Universidade Federal do Rio Grande Mestrandos do Programa de Pós-Graduação em Geografia

Adriano Luis Heck Simon Universidade Federal de Pelotas Professor Doutor do Programa de Pós-Graduação em Geografia adriano.simon@ufpel.edu.br

\section{1 - Introdução}

Constitui-se objetivo desta Nota Técnica informar à população Pelotense bem como a comunidade acadêmica e aos órgãos públicos ambientais, sobre a problemática resultante da construção do dique de contenção no Pontal da Barra (Pelotas/RS), a partir de uma análise geográfica dos conflitos de ordem natural e social. O dique foi construído devido às consequências da enchente ocorrida na região administrativa do Laranjal, mais precisamente na comunidade do Pontal da Barra e balneários Valverde e Novo Valverde (Figura 1), no mês de outubro de 2015. A enchente foi ocasionada por intensas precipitações que ocorreram de forma generalizada no Estado do Rio Grande do Sul, e que contribuíram para a elevação da vazão do Canal São Gonçalo e o aumento do nível da Laguna dos Patos (principais receptores das bacias de drenagem da margem atlântica 
gaúcha). O transbordamento dos cursos de água e dos corpos lagunares acabou desencadeando a ocupação das áreas úmidas adjacentes, regionalmente denominadas de banhados. Como consequência diversas famílias que habitam as áreas próximas ao banhado, à Laguna dos Patos e à zona de várzea do Canal São Gonçalo foram desabrigadas. A Prefeitura Municipal de Pelotas, numa tentativa de conter o avanço da água das enchentes, construiu um dique localizado sobre a principal zona de banhado do Pontal da Barra (Figura 1). Devido ao caráter emergencial da obra a prefeitura não apresentou estudos técnicos sobre a efetiva eficácia do dique, e nem das possíveis derivações ambientais ocasionadas em função da obra se localizar em um ambiente de zona úmida.

Figura1. Mapa de Localização do dique no Pontal da Barra, Pelotas/RS.

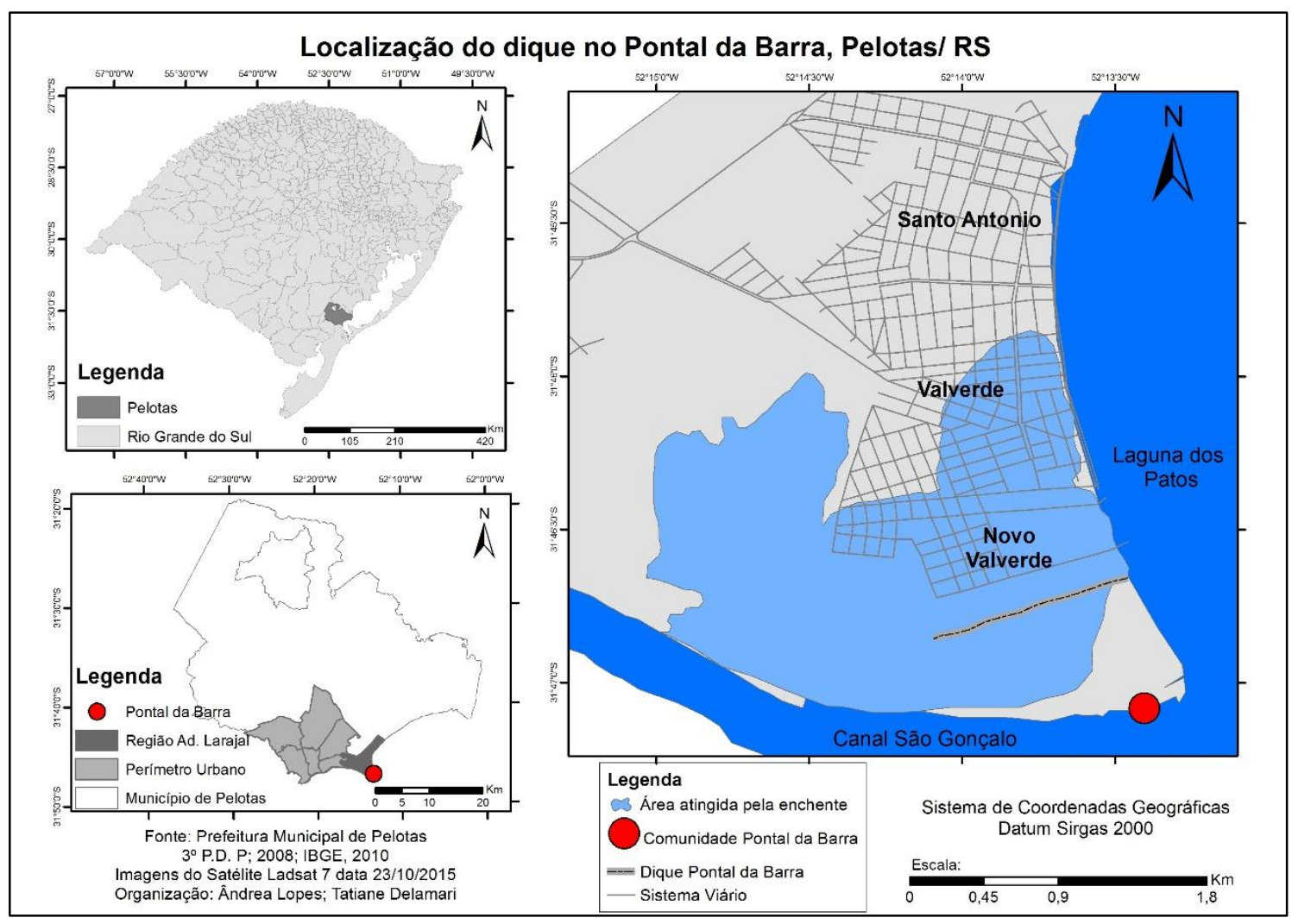

Fonte: Os autores, 2015.

O presente documento foi idealizado e redigido pelo grupo de pós-graduandos envolvidos com a disciplina de Ação Antrópica Sobre Sistemas Morfohidrográficos, do Programa de Pós-Graduação em Geografia (Mestrado Acadêmico) da Universidade Federal de Pelotas.

Esta análise se deu a partir de uma visita técnica desenvolvida no dia 29/10/15, junto às obras de construção do dique no Pontal da Barra. Neste dia, o grupo realizou um trabalho 
de campo atrelado às atividades da disciplina que, dentre vários pontos analisados, englobou o Pontal da Barra. Naquela ocasião pode-se verificar o momento crítico de conflito entre o avanço das águas do Canal São Gonçalo e da Laguna dos Patos sobre as áreas úmidas do Pontal da Barra, inclusive sobre as construções que se desenvolveram ao longo dos últimos anos naquela área. Também se pode avaliar uma série de questões vinculadas à construção do dique, como a característica dos materiais que foram utilizados para sua construção, se esta obra efetivamente cumprirá com a função a que se destina, bem como os impactos de sua construção

\section{2 - Desenvolvimento}

O Pontal da Barra se constitui em uma zona de tensão entre empreendimentos imobiliários formais, ocupações irregulares, leis de proteção ambiental, biodiversidade peculiar e registros arqueológicos. A área se caracteriza também por ser um ponto extremamente crítico em relação à circulação de água e sedimentos em uma região estuarina (circulação de água doce e salgada) e de confluência das hidrodinâmicas dos sistemas lagunares Patos-Mirim, responsáveis pela drenagem de importantes sistemas fluviais do Estado do Rio Grande do Sul e de parte do território Uruguaio.

Segundo o Plano Ambiental Municipal (2013), Pelotas possui apenas o Pontal da Barra como Unidade de Conservação, reconhecido em nível estadual e nacional. De acordo com o Sistema Estadual de Unidades de Conservação (SEUC), o Pontal é enquadrado como Reserva Particular de Patrimônio Natural (RPPN). Para Oliveira (2010, p.19)

A RPPN é a única unidade de conservação de uso sustentável que só permite o uso indireto dos recursos naturais. Desta forma, observa-se que, na prática, ela funciona como unidade de conservação de proteção integral, considerando que só são permitidas atividades de pesquisa e ecoturismo.

O que se percebe na RPPN do Pontal da Barra é uma profunda falta de compreensão entre as relações entre os sistemas lagunares e as áreas úmidas de banhado, evidenciada pela franca expansão de aterramentos para a construção de estradas e loteamentos, depósitos inadequados de resíduos sólidos urbanos ${ }^{1}$, bem como tentativas forçadas de urbanização e impermeabilização de superfícies de banhado.

\footnotetext{
${ }^{1}$ São aqueles provenientes da atividade domiciliar e dos serviços de limpeza urbana (BRASIL, 2012).
} 
A visita técnica possibilitou uma melhor compreensão do dique enquanto mecanismo de controle antrópico sobre o sistema natural da área. Foi possível verificar que a construção desta obra é inadequada como um meio de proteção à população, pois o material utilizado para a construção do dique é composto por sedimentos areno-argilosos inconsolidados, provenientes da remobilização local e também de outras áreas (Figura 2). Este material é extremamente suscetível aos processos plúvio-erosivos, que podem ocasionar a desagregação do material e organização de feições erosivas lineares, como sulcos identificados em campo (Figura 3). A evolução dessas feições erosivas pode levar a fragilização da estrutura e consequente rompimento do dique. Por se tratar de um material com grande concentração de argila seu ressecamento pode desencadear a evolução de fraturas que podem atuar no colapso do mesmo em situação de pressões ocasionadas pela água contida. Isso faz com que em uma nova situação de enchente, caso ocorra o rompimento desse dique, a água chegue com maior velocidade e de forma mais rápida as residências, diminuindo o tempo de evacuação da área. Conforme Tucci (2003, p. 72) “o maior risco existente na construção de um dique é a definição correta de enchente máxima provável, pois existirá sempre um risco de colapso, quando os danos serão piores se o mesmo não existisse".

Figura 2. Construção do dique

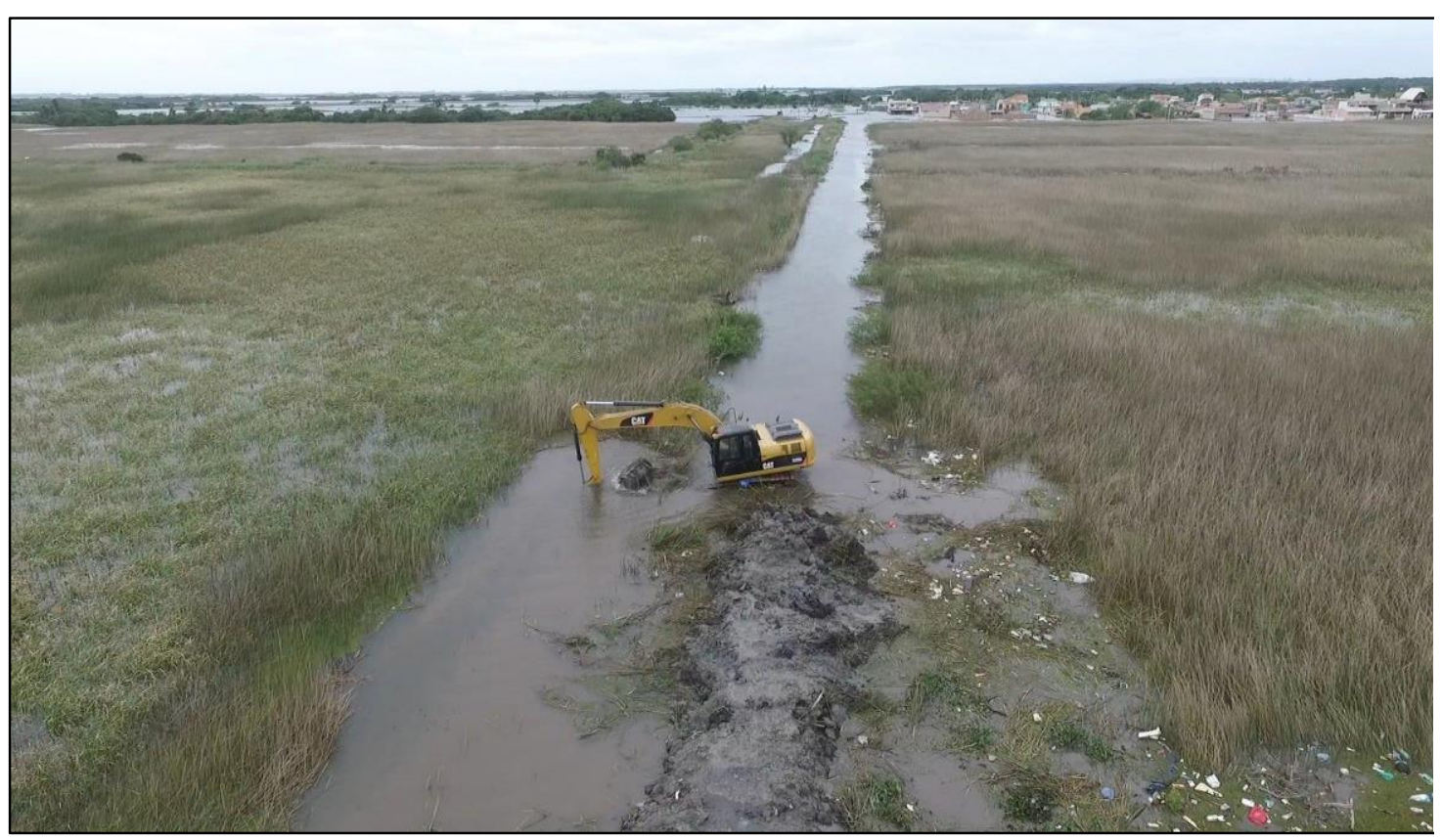

Obra de construção do dique: verifica-se a remobilização do material adjacente, predominantemente argiloso, altamente suscetível à erosão pluvial. Fonte: Topcam, 2015. 
Figura 3. Material de composição do dique

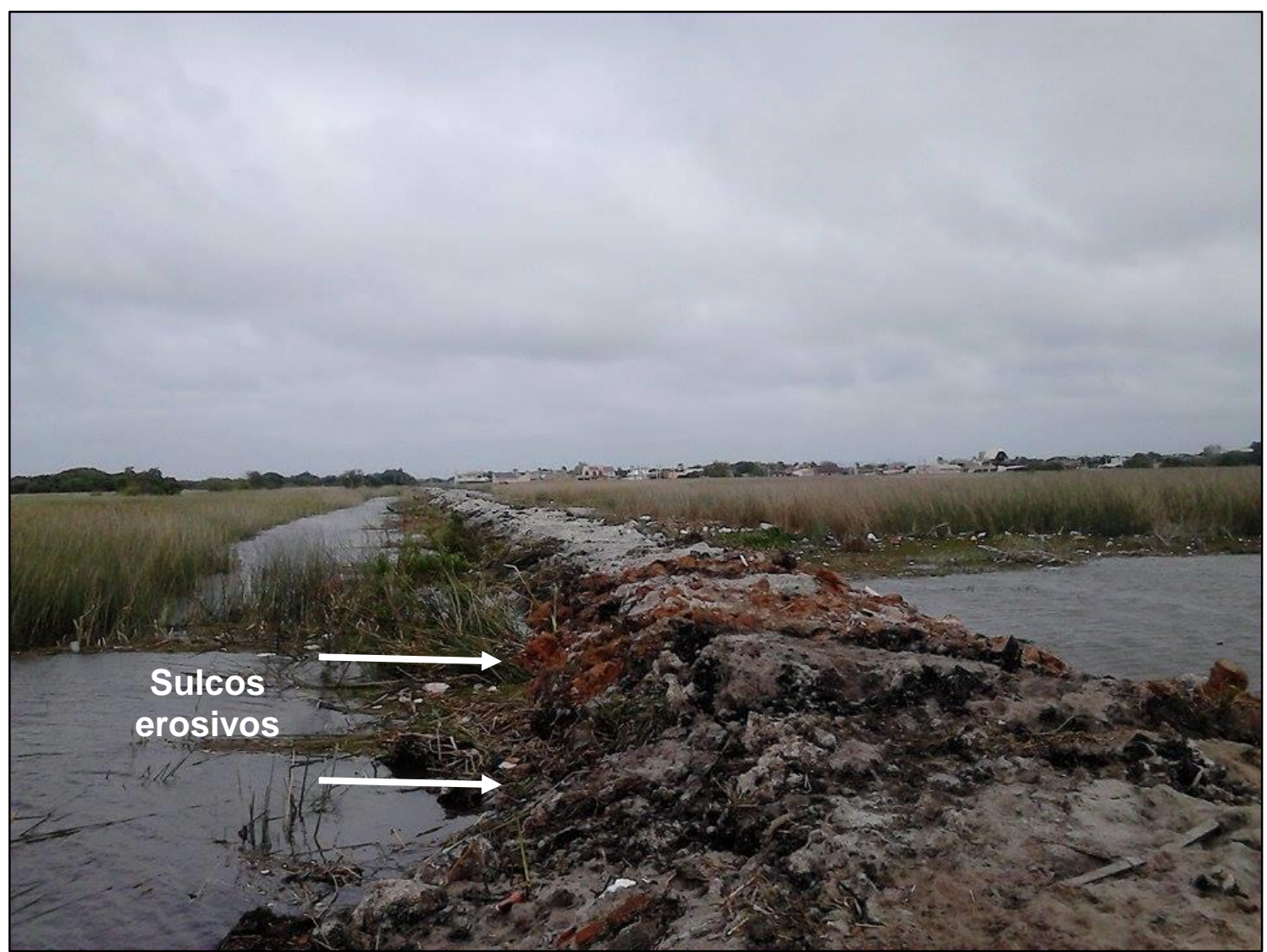

Registro fotográfico da situação do dique três dias após a construção finalizada: verifica- se a ocorrência de feições erosivas lineares (sulcos), iniciando processos de desagregação do material, demostrando a fragilidade da construção que, consequentemente, pode acarretar no rompimento do dique. Fonte: Acervo pessoal, 2015.

As condições geológicas, geomorfológicas e pedológicas da área (superfícies planas, de sedimentação recente e suscetíveis ao acúmulo de água) tornam possível a ocorrência de percolação da água em subsuperfície, favorecendo o fluxo e a dispersão hidrológica entre os dois lados do dique, anulando sua existência. Segundo Horton (1933), citado por Cunha e Guerra (2005, p.118) “o termo percolação se refere ao fluxo em subsuperfície que atravessa a zona de aeração em direção ao nível freático, o qual delimita a porção extrema superior da zona saturada do solo".

Além disso, por ser uma área de banhado, onde há uma grande biodiversidade, é necessário que seja realizado um estudo sobre espécies que possam ser afetadas pela criação dessa barreira e tenham seu fluxo gênico seccionado. De acordo com o Plano Ambiental Municipal (2013, p.37) 
A região da RPPN do Pontal da Barra alberga uma elevada biodiversidade, distribuída em ambientes como banhados, charcos temporários, matas nativas e campos inundáveis. $\mathrm{Na}$ mesma foram registradas mais de 200 espécies de aves, mais de 100 espécies de peixes, pelos menos duas dezenas de mamíferos e entre 30 e 40 de répteis e anfíbios. Entre as espécies de peixes estão duas ameaçadas de extinção, em nível nacional e estadual.

Acredita-se que o conjunto de impactos e degradações ambientais verificados no Pontal da Barra é decorrente de um conjunto de ações públicas e privadas que se acumularam no tempo e no espaço, sendo que muitos destes já se encontram consolidados (área urbanizadas regulares e irregulares), enquanto outros ainda podem ser recuperados (depósitos de resíduos sólidos e demais impactos em áreas úmidas).

\section{3 - Conclusão}

Entende-se que diante desse quadro e procurando evitar futuras situações similares a enfrentada, o grupo autor dessa nota propõe que sejam considerados e atendidos um conjunto de medidas que possam a curto, médio e longo prazo, amenizar e converter a problemática evidenciada:

(1) Caso persista a manutenção do dique e/ou a construção de outras formas de contenção da água, sugere-se que estas ações ocorram na perspectiva de sua maior proximidade possível com as construções já efetivadas, a fim de evitar a maior pressão sobre as áreas úmidas e consequentemente atuar no impedimento da expansão de novos loteamentos em direção às áreas úmidas de banhado.

(2) Compreendendo que esta foi uma obra realizada em caráter emergencial, não foram considerados todos os aspectos da dinâmica socioambiental do local. Assim, sugerimos que passada a fase crítica das cheias o poder púbico discuta com a população Pelotense, com a comunidade acadêmica e os órgãos ambientais competentes a magnitude da referida obra: Quais os impactos ambientais e sociais atrelados à construção deste dique? Como se dará a manutenção e monitoramento da obra para que os processos acima descritos não venham a ocorrer colocando em risco as populações adjacentes?

(3) Ainda, salienta-se que a população residente do Pontal da Barra continua em situação de vulnerabilidade independente da medida adotada, pois acredita-se que o dique beneficia somente as construções urbanas do Novo Valverde e do Valverde.

Diante das questões expostas sugerimos e lançamos algumas proposições: 
- que se faça uma audiência pública com a comunidade envolvida e principalmente com a população atingida;

- que o assunto seja pauta do Conselho Municipal de Proteção Ambiental - COMPAM, com convite às ONG's ambientais locais;

- que os responsáveis pela construção do dique elaborem e divulguem o projeto, bem como o licenciamento ambiental, mesmo que retroativo.

Por fim, diante das manifestações expostas nesta nota técnica, sugerimos que o poder público municipal de Pelotas passe a adotar medidas preventivas e não emergenciais corretivas para essa situação de conflitos entre o processo de ocupação e o sistema físicoambiental do Pontal da Barra.

\section{REFERÊNCIAS}

BRASIL [Lei n. 12.305 de 2 de agosto de 2010]. Política Nacional de Resíduos Sólidos [recurso eletrônico]. $2^{\circ}$ Ed. Brasília: Edições Câmara, 2012.

CUNHA, S. B.; GUERRA, A. J. T. Geomorfologia: uma atualização de Bases e Conceitos. $6^{\mathrm{a}}$ ed. Rio de Janeiro: Bertrand Brasil, 2005. 472 p.

OLIVEIRA, J. C. C.; BARBOSA, J. H. C. Roteiro para criação de unidades de conservação municipais. Brasília, DF: Ministério do Meio Ambiente, 2010.

PREFEITURA MUNICIPAL DE PELOTAS. Plano ambiental de Pelotas. Disponível em: < http://www.pelotas.rs.gov.br/qualidade-ambiental/plano-municipal/> Acesso em: 06 de dezembro de 2015.

TUCCI. C. E. M.; BERTONI, J. C. (Orgs). Inundações Urbanas na América do Sul. Porto Alegre: Associação Brasileira de Recursos Hídricos, 2003. 